\title{
Photodissociation of Cyclobutyl Bromide at 234 nm Studied Using Velocity Map Imaging ${ }^{\dagger}$
}

\author{
Yi Liu, Kai-Chung Lau, and Laurie J. Butler* \\ James Franck Institute and Department of Chemistry, The University of Chicago, Chicago, Illinois 60637
}

Received: October 30, 2005; In Final Form: February 9, 2006

\begin{abstract}
This study investigates the $234 \mathrm{~nm}$ photodissociation dynamics of cyclobutyl bromide using a two-dimensional photofragment velocity imaging technique. The spin-orbit ground- and excited-state $\mathrm{Br}\left({ }^{2} \mathrm{P}\right)$ atoms are stateselectively detected via [2+1] resonance enhanced multiphoton ionization (REMPI), whereas the cyclobutyl radicals are ionized using $157 \mathrm{~nm}$ laser light. The $\operatorname{Br}\left({ }^{2} \mathrm{P}_{3 / 2}\right)$ and the $\operatorname{Br}\left({ }^{2} \mathrm{P}_{1 / 2}\right)$ atoms and their $c-\mathrm{C}_{4} \mathrm{H}_{7}$ radical cofragments evidence a single-peaked, Gaussian-shaped translational energy distribution ranging from $\sim 14$ to $\sim 39 \mathrm{kcal} / \mathrm{mol}$ and angular distributions with significant parallel character. The $\operatorname{Br}\left({ }^{2} \mathrm{P}_{1 / 2}\right) / \operatorname{Br}\left({ }^{2} \mathrm{P}_{3 / 2}\right)$ spinorbit branching ratio is determined to be $0.11 \pm 0.07$ by momentum match between the $\mathrm{Br}\left({ }^{2} \mathrm{P}\right)$ photofragments and the recoiling $c-\mathrm{C}_{4} \mathrm{H}_{7}$ fragments, assuming a uniform photoionization probability of the $c-\mathrm{C}_{4} \mathrm{H}_{7}$ radicals with an internal energy range of $10-35 \mathrm{kcal} / \mathrm{mol}$. The REMPI line strength ratio for the detection of $\operatorname{Br}\left({ }^{2} \mathrm{P}_{3 / 2}\right)$ and $\operatorname{Br}\left({ }^{2} \mathrm{P}_{1 / 2}\right)$ atoms at 233.681 and $234.021 \mathrm{~nm}$, respectively, is therefore derived to be $0.10 \pm 0.07$. The measured recoil kinetic energies of the $c-\mathrm{C}_{4} \mathrm{H}_{7}$ radicals, and the resulting distribution of internal energies, indicates some of the radicals are formed with total internal energies above the barrier to isomerization and subsequent dissociation, but our analysis indicates they may be stable due to the substantial fraction of the internal energy which is partitioned to rotational energy of the radicals.
\end{abstract}

\section{Introduction}

There has been substantial interest in the unimolecular decomposition reaction dynamics of unsaturated and saturated hydrocarbon radicals in recent years because they serve as the intermediate species along the reaction coordinate of many bimolecular interactions important to combustion chemistry. ${ }^{1-5}$ In these studies, hydrocarbon halides are the most commonly used photolytic precursors to produce these radicals since they are often commercially available and the $\mathrm{C}-\mathrm{X}$ bond fission channel upon excitation with an ultraviolet photon usually has a large relative quantum yield. Photodissociation of these molecules in their UV absorption band typically produce halogen atoms $(\mathrm{X})$ both in the spin-orbit ground state $\left({ }^{2} \mathrm{P}_{3 / 2}\right)$ and excited state $\left({ }^{2} \mathrm{P}_{1 / 2}\right)$. Because the spin-orbit splitting for $\mathrm{Cl}\left({ }^{2} \mathrm{P}\right)$ is small, if the $\mathrm{X}\left({ }^{2} \mathrm{P}\right)$ atoms cannot be state-selectively distinguished, the chloro-hydrocarbon molecules are preferred for determining the internal energies of the hydrocarbon radicals by momentum match with the $\mathrm{Cl}$ cofragments and by conservation of energy. Indeed, quite a few studies on chlorine substituted systems have been demonstrated to be successful for the determination of the hydrocarbon radicals' secondary dissociation barrier heights. ${ }^{1,2,5}$ However, due to the strong carbon-chlorine, hydrogenchlorine interactions and the small steric hindrance of chlorine atoms, dissociation of chlorohydrocarbon molecules often involves other complications such as isomerization, $\mathrm{H}$ atom elimination, and $\mathrm{C}-\mathrm{C}$ bond fission, followed by secondary dissociations. ${ }^{6,7}$ These competing product channels can make characterization of the primary $\mathrm{Cl}$ atom elimination channels problematic. One example is the photodissociation of vinyl chloride at $193 \mathrm{~nm}$ by Blank et al., ${ }^{7}$ where they observed five primary dissociation channels following an initial $\pi^{* \leftarrow \pi}$ excitation. Therefore, chlorinated hydrocarbons may not be good

\footnotetext{
† Part of the special issue "John C. Light Festschrift".

* To whom correspondence should be addressed. E-mail: L-Butler@ uchicago.edu.
}

precursors for the corresponding radicals. In contrast, the primary photodissociation of alkyl or alkenyl bromides is more straightforward, with a dominant $\mathrm{C}-\mathrm{Br}$ fission channel and some contribution from $\mathrm{HBr}$ elimination. Once the $\mathrm{Br}$ atom spin-orbit states can be state-specifically detected, along with the kinetic energy releases, the internal energy of the recoiling hydrocarbon radicals can be accurately determined, and alkyl or alkenyl bromides actually serve as better radical precursors.

There have been a number of studies on the UV photodissociation of alkyl or alkenyl bromides in the literature. . $^{3,4,-13}$ Gougousi et al. ${ }^{8}$ extensively investigated the photolysis of methyl bromide in the first continuum, resolving the $\operatorname{Br}\left({ }^{2} \mathrm{P}_{3 / 2}\right) /$ $\operatorname{Br}\left({ }^{2} \mathrm{P}_{1 / 2}\right)$ spin- orbit branching ratio, the partial absorption cross section, as well as the vibrational distribution of the nascent $\mathrm{CH}_{3}$ radicals. Park et al. ${ }^{10}$ studied the $235 \mathrm{~nm}$ photodissociation dynamics of allyl bromide and found a single-peaked product translational energy distribution $\left(\mathrm{P}\left(\mathrm{E}_{\mathrm{T}}\right)\right)$, unlike that of the allyl chloride $\mathrm{P}\left(\mathrm{E}_{\mathrm{T}}\right)$. A series of $n$-alkyl bromides were studied at 234 and $267 \mathrm{~nm}$ by Zhu et al. ${ }^{9}$ the study determined the relative quantum yields of the $\operatorname{Br}\left({ }^{2} \mathrm{P}_{3 / 2}\right)$ and $\operatorname{Br}\left({ }^{2} \mathrm{P}_{1 / 2}\right)$ fragments and rationalized the observed trends. Morton et al. ${ }^{3}$ and Miller et al. ${ }^{4}$ investigated the $193 \mathrm{~nm}$ photodissociation of 1-bromopropene and 2-bromo-1-butene, respectively, using tunable vacuum ultraviolet (VUV) photoionization of the photofragments. Though they showed the $\mathrm{Br}$ atoms were primarily produced in the $\operatorname{Br}\left({ }^{2} \mathrm{P}_{3 / 2}\right)$ spin-orbit state, the contribution of $\operatorname{Br}\left({ }^{2} \mathrm{P}_{1 / 2}\right)$ fragments could not be quantified due to contamination of higher harmonics in the VUV photoionization source.

So far, photodissociation studies in the ultraviolet have mainly focused on noncyclic alkyl and alkenyl bromides. Possessing higher symmetry than the straight-chain homologous compounds and a propensity to ring-opening and other isomerization, cyclic hydrocarbon radicals have drawn considerable attention in physical organic chemistry. ${ }^{14,15}$ Nevertheless, there have been a few studies on the photolysis of cyclic hydrocarbon halides. 
One example is the search for an appropriate cyclopropyl radical precursor. Arnold et al. ${ }^{16}$ have performed a photodissociation study of cylcopropyl iodide at 266 and $279.7 \mathrm{~nm}$ using ion imaging for the gas phase and TEMPO-trapping to detect the radical products from the solution-phase photodissociation. In neither case did they observe the cyclobutyl radical as a direct dissociation product from photoexcited cyclobutyl iodide. Clegg et al. ${ }^{17}$ used time-resolved Fourier transform spectroscopy and photofragment ion imaging to study the photodissociation of dicyclopropyl ketone at $193 \mathrm{~nm}$ and they also did not observe any stable cyclopropyl radical. Another example is the stateselective photofragment translational spectroscopy of iodocyclohexane studied by Freitas et al. ${ }^{18}$ By monitoring the $\mathrm{I}\left({ }^{2} \mathrm{P}_{\mathrm{J}}\right)$ fragments' translational energy and angular distribution, they were able to determine the energy difference of the axial and equatorial conformers of iodocyclohexane.

In this paper, we present a $234 \mathrm{~nm}$ photodissociation study of the $\mathrm{C}-\mathrm{Br}$ bond fission of cyclobutyl bromide using the velocity map imaging method. Angular and translational energy distributions of the nascent $\operatorname{Br}\left({ }^{2} \mathrm{P}_{3 / 2}\right)$ and $\operatorname{Br}\left({ }^{2} \mathrm{P}_{1 / 2}\right)$ atoms and the $c-\mathrm{C}_{4} \mathrm{H}_{7}$ radicals are measured. In addition to this, the spinorbit branching ratio of $\mathrm{Br}$ atomic fragments is deduced by comparing the total $\mathrm{C}-\mathrm{Br}$ bond fission $\mathrm{P}\left(\mathrm{E}_{\mathrm{T}}\right)$ obtained from the $c-\mathrm{C}_{4} \mathrm{H}_{7}$ radical photofragments and that from the $\mathrm{Br}\left({ }^{2} \mathrm{P}_{3 / 2,1 / 2}\right)$ products. To make the comparison between the $\mathrm{P}\left(\mathrm{E}_{\mathrm{T}}\right)$ 's derived from velocity measurements of each of the momentum-matched photofragments possible, one must measure the total $\mathrm{P}\left(\mathrm{E}_{\mathrm{T}}\right)$ appropriately summed over all quantum states of the photofragments. When the photofragments are probed by stateselective photoionization, one has to reconstruct the total $\mathrm{P}\left(\mathrm{E}_{\mathrm{T}}\right)$ with line strength corrections, which are unknown for most polyatomic radical species. Thus, we use nonstate-selective 157$\mathrm{nm}$ photoionization to detect all of the $c-\mathrm{C}_{4} \mathrm{H}_{7}$ fragments formed in the $234 \mathrm{~nm}$ photodissociation with equal efficiency. The ionization energy of the $c-\mathrm{C}_{4} \mathrm{H}_{7}$ radical is near $7.6 \mathrm{eV}$, which is accessible by a $157-\mathrm{nm} \mathrm{F}_{2}$ excimer laser. The resulting $\mathrm{P}\left(\mathrm{E}_{\mathrm{T}}\right)$ obtained should accurately represent the quantum yield weighted sum of the quantum-state-resolved $\mathrm{P}\left(\mathrm{E}_{\mathrm{T}}\right)$ 's if the photoionization cross section is independent of the internal energy of the radical for the population of nascent radicals. The atomic $\operatorname{Br}\left({ }^{2} \mathrm{P}_{3 / 2}\right)$ and $\operatorname{Br}\left({ }^{2} \mathrm{P}_{1 / 2}\right)$ fragments are probed by resonance-enhanced multiphoton ionization (REMPI) at 233.681 and $234.021 \mathrm{~nm}$, respectively. The total $\mathrm{C}-\mathrm{Br}$ bond fission $\mathrm{P}\left(\mathrm{E}_{\mathrm{T}}\right)$ is then reconstructed by the weighted average of the $\mathrm{P}\left(\mathrm{E}_{\mathrm{T}}\right)$ 's derived from the individual $\operatorname{Br}\left({ }^{2} \mathrm{P}_{3 / 2}\right)$ and $\operatorname{Br}\left({ }^{2} \mathrm{P}_{1 / 2}\right)$ fragments. The weighting factor, i.e., spin-orbit branching ratio, is determined by matching the $\mathrm{P}\left(\mathrm{E}_{\mathrm{T}}\right)$ obtained from the kinetic-energy release measurements of $c-\mathrm{C}_{4} \mathrm{H}_{7}$ fragments with that of the atomic $\mathrm{Br}$ cofragments as both the $\mathrm{P}\left(\mathrm{E}_{\mathrm{T}}\right)$ 's must be matched on the basis of momentum and energy conservation. (This is the case as long as none of the $c-\mathrm{C}_{4} \mathrm{H}_{7}$ fragments undergoes dissociation or isomerizes to a form that is not detected as efficiently in the VUV ionization.) We use the spin-orbit branching ratio thus determined to derive the REMPI line strength ratio of the $\operatorname{Br}\left({ }^{2} \mathrm{P}_{3 / 2}\right)$ and $\operatorname{Br}\left({ }^{2} \mathrm{P}_{1 / 2}\right)$ atoms at 233.681 and $234.021 \mathrm{~nm}$, respectively. We compare our result to that in a previous study by Jee et al. ${ }^{19}$

\section{Experimental Section}

The experimental two-dimensional photofragment velocity map imaging apparatus has been described in detail previously. ${ }^{20-22}$ Cyclobutyl bromide (stated purity 97\%) was purchased from Aldrich and used without further purification. The molecular beam is formed by expanding 300 Torr of helium containing about $3 \%$ cyclobutyl bromide vapor through a room- temperature pulsed valve (General Valve) with a $0.6 \mathrm{~mm}$ orifice which is driven by a voltage pulse of $300 \mu$ s width. After passing through a skimmer located $\sim 20 \mathrm{~mm}$ downstream from the nozzle, the molecular beam travels another $51 \mathrm{~mm}$ to the center of the reaction chamber.

The $532 \mathrm{~nm}$ output of a pulsed injection-seeded Nd:YAG (yttrium-aluminum-garnet) continuum laser was used to pump a dye laser (Lambda Physik, FL3002, LDS698 dye), generating visible radiation in the region of $675-715 \mathrm{~nm}$. The dye laser output was frequency doubled in a KDP (potassium dihydrogen phosphate) crystal and the resulting $351 \mathrm{~nm}$ light was mixed with the $701 \mathrm{~nm}$ fundamental in a BBO (beta-barium borate) crystal to produce the $234 \mathrm{~nm}$ photons. A focusing lens $(\sim 109$ $\mathrm{mm}$ focal length) was used to focus the $234 \mathrm{~nm}$ laser beam into the interaction region. The $234 \mathrm{~nm}$ light is linearly polarized along an axis vertically perpendicular to the molecular beam and parallel to the detector surface.

The parent cyclobutyl bromide molecules were dissociated by the $234 \mathrm{~nm}$ photons and the resulting $\operatorname{Br}\left({ }^{2} \mathrm{P}_{3 / 2}\right)$ and $\operatorname{Br}\left({ }^{2} \mathrm{P}_{1 / 2}\right)$ fragments were ionized via [2+1] resonance enhanced multiphoton ionization (REMPI) at $233.681 \mathrm{~nm}\left(5 \mathrm{p}{ }^{4} \mathrm{P}_{1 / 2} \leftarrow 4 \mathrm{p}^{2} \mathrm{P}_{3 / 2}\right)$ and $234.021 \mathrm{~nm}\left(5 \mathrm{p}^{2} \mathrm{~S}_{1 / 2} \leftarrow 4 \mathrm{p}^{2} \mathrm{P}_{1 / 2}\right)$, respectively. ${ }^{9}$ The $c-\mathrm{C}_{4} \mathrm{H}_{7}$ fragments formed in the photodissociation of cyclobutyl bromide were ionized using $157 \mathrm{~nm}$ VUV photons ${ }^{23}$ produced by a $\mathrm{F}_{2}$ excimer laser (GAM EX10F/300). The $157 \mathrm{~nm}$ laser was focused into the reaction chamber by a magnesium fluoride focusing lens with $64 \mathrm{~mm}$ focal length and the light path outside the chamber was purged with nitrogen gas. During the experiment, the $234 \mathrm{~nm}$ laser wavelength was scanned over the entire Doppler profile of the REMPI lines while detecting the $\operatorname{Br}\left({ }^{2} \mathrm{P}_{1 / 2}\right)$ and $\operatorname{Br}\left({ }^{2} \mathrm{P}_{3 / 2}\right)$ photofragments. The photolysis and ionization laser power and the cyclobutyl bromide molecular density in the interaction region are carefully monitored to minimize space charge effects.

The spherically expanding ion clouds formed in the photodissociation/photoionization were accelerated toward a twodimensional position-sensitive detector by an electrical ion lens assembly with an extractor/repeller voltages ratio of 0.712 . After flying through the time-of-flight (TOF) drift region $(\sim 577 \mathrm{~mm})$, the ions strike the detector (Burle 3040FM) which consists of a chevron microchannel plate (MCP) coupled with a P20 phosphor screen by fiber optics. To detect only the ions of interest, the front plate of the MCP was pulsed to $-750 \mathrm{~V}$ at the appropriate arrival time with a width of $\sim 70 \mathrm{~ns}$. The phosphor screen was maintained at $3.5 \mathrm{kV}$ above the potential of the rear MCP plate. Images appearing on the phosphor screen were recorded by a $1376 \times 1040$ pixel charge-coupled device camera (LaVision Imager 5) with a standard $35 \mathrm{~mm}$ camera lens. The ion signal was collected with the event-counting method, using the algorithm integrated in the DaVis software, and each image was accumulated for over one hundred thousand laser shots. The timing sequence for opening of the pulsed valve, firing of the $\mathrm{Nd}$ :YAG and $\mathrm{F}_{2}$ excimer lasers, pulsing the MCP and capturing the ion images were controlled by a digital pulse generator (Stanford Research System DG535) at a repetition rate of $20 \mathrm{~Hz}$.

\section{Results and Discussion}

A. Translational Energy Distributions. This experiment investigates the following reaction:

$c-\mathrm{C}_{4} \mathrm{H}_{7} \mathrm{Br} \rightarrow c-\mathrm{C}_{4} \mathrm{H}_{7}+\mathrm{Br}\left({ }^{2} \mathrm{P}_{1 / 2,3 / 2}\right) \quad \Delta H_{0 \mathrm{~K}}=74.0 \mathrm{kcal} / \mathrm{mol}$

at $234 \mathrm{~nm}$. The $\mathrm{C}-\mathrm{Br}$ bond dissociation energy was calculated 

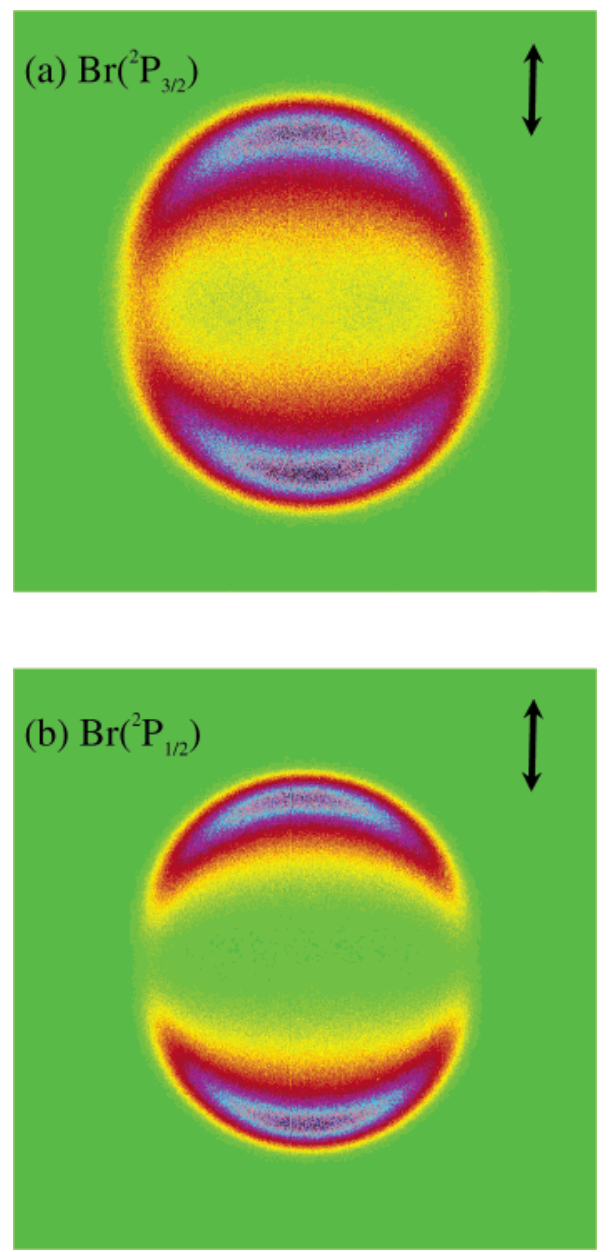

Figure 1. Raw images of (a) $\operatorname{Br}\left({ }^{2} \mathrm{P}_{3 / 2}\right)$ obtained with dissociation and probe at $233.681 \mathrm{~nm}$ via the $5 \mathrm{p}{ }^{4} \mathrm{P}_{1 / 2} \leftarrow 4 \mathrm{p}{ }^{2} \mathrm{P}_{3 / 2}$ transition; (b) $\mathrm{Br}\left({ }^{2} \mathrm{P}_{1 / 2}\right)$ obtained with dissociation and probe at $234.021 \mathrm{~nm}$ via the $5 \mathrm{p}^{2} \mathrm{~S}_{1 / 2} \leftarrow$ $4 p^{2} \mathrm{P}_{1 / 2}$ transition. The laser polarization is along the vertical direction in the plane of the images. Each image consists of $861 \times 861$ pixels and is constructed by accumulating signals from approximately 200000 laser shots. The distance of 1.0 centimeter on the phosphor screen corresponds to the width of 221.6 pixels in the images and $882 \mathrm{~m} / \mathrm{s} \mathrm{Br}$ atom recoil velocity.

at the Gaussian-3 (G3) level of theory using the Gaussian 03 package. ${ }^{24}$ Assuming effective rotational cooling in the supersonic expansion, the parent cyclobutyl bromide molecules were estimated to have an average of $1.2 \mathrm{kcal} / \mathrm{mol}$ of internal energy using the $298 \mathrm{~K}$ vibrational frequencies calculated at the B3LYP/ 6-31G(d) level of theory. The energy available to partition between product recoil translational energy and internal energy of the nascent cyclobutyl radical and bromine atom spin-orbit energy is thus $48.7 \mathrm{kcal} / \mathrm{mol}$. As the experiment is a one-color process while detecting the $\operatorname{Br}\left({ }^{2} \mathrm{P}_{1 / 2,3 / 2}\right)$ fragments, the photodissociation wavelength varies slightly with the specific spinorbit state of the Br atoms probed. The UV absorption spectrum (Figure 8) of cyclobutyl bromide displays a broad, featureless peak around $200 \mathrm{~nm}$, and the energy difference of the two REMPI resonance wavelengths we are using is only $62 \mathrm{~cm}^{-1}$. Thus the difference between photodissociation cross sections at these closely spaced REMPI lines can be neglected.

Ion images of the $\operatorname{Br}\left({ }^{2} \mathrm{P}_{3 / 2}\right)$ and $\operatorname{Br}\left({ }^{2} \mathrm{P}_{1 / 2}\right)$ photofragments are shown in Figure 1, with the $234 \mathrm{~nm}$ laser polarization direction in the vertical axis. Each image similarly displays a single high kinetic energy release component distributed in the polar regions. Three-dimensional photofragment scattering distributions are reconstructed using the Gaussian basis-set expansion Abel

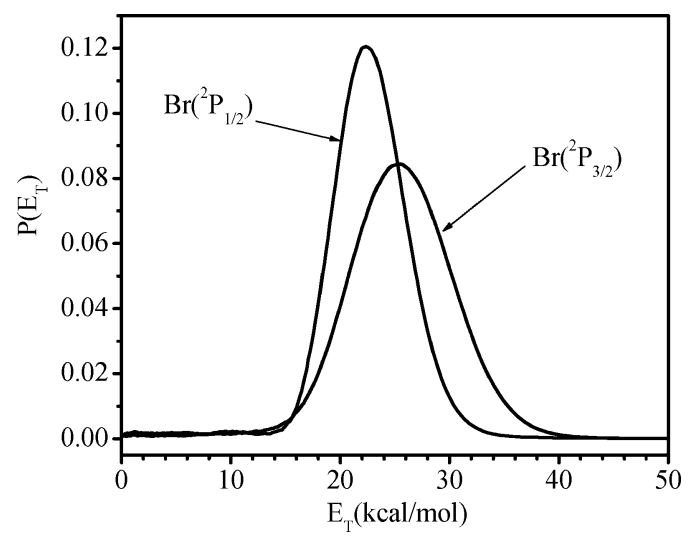

Figure 2. $c-\mathrm{C}_{4} \mathrm{H}_{7}+\mathrm{Br}\left({ }^{2} \mathrm{P}_{1 / 2,3 / 2}\right)$ center-of-mass translational energy distributions derived from Figure 1.

transformation method developed by Dribinski et al. ${ }^{25}$ The speed distributions of the $\operatorname{Br}\left({ }^{2} \mathrm{P}_{1 / 2,3 / 2}\right)$ fragments are extracted by integrating the three-dimensional speed distributions over all solid angles at each speed and the total center-of-mass translational energy distributions, $\mathrm{P}\left(\mathrm{E}_{\mathrm{T}}\right)$ 's, are derived from the $\operatorname{Br}\left({ }^{2} \mathrm{P}_{1 / 2,3 / 2}\right)$ atom speed distributions using conservation of momentum and correcting for the appropriate Jacobian. The results are presented in Figure 2, where the peak value of translational energy release in the $\mathrm{C}-\mathrm{Br}$ fission channel which produces $\operatorname{Br}\left({ }^{2} \mathrm{P}_{3 / 2}\right)$ atoms is $25.5 \mathrm{kcal} / \mathrm{mol}$, and that producing $\mathrm{Br}\left({ }^{2} \mathrm{P}_{1 / 2}\right)$ is $22.4 \mathrm{kcal} / \mathrm{mol}$. The $\mathrm{C}-\mathrm{Br}$ bond fission proceeds on a repulsive electronic state, and the lower recoil kinetic energies in the $\operatorname{Br}\left({ }^{2} \mathrm{P}_{1 / 2}\right)$ channel likely reflect the lower available energy for that channel due to the substantial $(10.54 \mathrm{kcal} / \mathrm{mol}) \mathrm{spin}-$ orbit splitting between the ${ }^{2} \mathrm{P}_{3 / 2}$ and ${ }^{2} \mathrm{P}_{1 / 2}$ states of the $\mathrm{Br}$ atoms. The difference $(2.1 \mathrm{kcal} / \mathrm{mol})$ is notably smaller than the actual $\operatorname{Br}\left({ }^{2} \mathrm{P}_{1 / 2}\right) / \operatorname{Br}\left({ }^{2} \mathrm{P}_{3 / 2}\right)$ spin-orbit energy, so less internal energy is partitioned into the $c-\mathrm{C}_{4} \mathrm{H}_{7}$ radical cofragments in the channel producing $c-\mathrm{C}_{4} \mathrm{H}_{7}+\mathrm{Br}\left({ }^{2} \mathrm{P}_{1 / 2}\right)$.

The raw images of $c-\mathrm{C}_{4} \mathrm{H}_{7}$ photofragments taken at $234+$ 157 and $157 \mathrm{~nm}$ are shown in Figure 3, panels a and b, respectively. Both 157 and $234 \mathrm{~nm}$ lasers can photodissociate the cyclobutyl bromide molecules, but only the $157 \mathrm{~nm}$ photons are energetic enough to ionize the $c-\mathrm{C}_{4} \mathrm{H}_{7}$ radicals. Thus, the $\mathrm{P}\left(\mathrm{E}_{\mathrm{T}}\right)$ of the $m / e=55$ signal from $234 \mathrm{~nm}$ photodissociation can be obtained by subtracting the signal at $157 \mathrm{~nm}$ from the signal at $234+157 \mathrm{~nm}$. The resultant $\mathrm{P}\left(\mathrm{E}_{\mathrm{T}}\right)$ after subtraction is displayed as the solid curve in Figure 4. The total recoil translational energy release in these processes spans the range of $14.0-39.0 \mathrm{kcal} / \mathrm{mol}$, and peaks at approximately $24.5 \mathrm{kcal} / \mathrm{mol}$.

Based on conservation of energy, the $c-\mathrm{C}_{4} \mathrm{H}_{7}$ radicals produced in the $234 \mathrm{~nm}$ photodissociation of cyclobutyl bromide have an internal energy distribution that ranges from 9.7 to 34.7 $\mathrm{kcal} / \mathrm{mol}$. There are a number of possible isomerization and dissociation pathways of the $c-\mathrm{C}_{4} \mathrm{H}_{7}$ radicals, and the barriers to many of these pathways have been calculated in prior studies by Miller et al. ${ }^{26}$ and by Matheu et al. ${ }^{14}$ The energy levels of the reactant species and barrier heights predicted at the G3// B3LYP level are depicted in Figure 5. As shown in the figure, the $c-\mathrm{C}_{4} \mathrm{H}_{7}$ radical could undergo ring opening and isomerization to form the 3-buten-1-yl $\left(\mathrm{CH}_{2} \mathrm{CHCH}_{2} \mathrm{CH}_{2}\right)$ radical via a transition barrier of $28.3 \mathrm{kcal} / \mathrm{mol}$. The 3 -buten-1-yl radicals could further convert to 1-methylallyl $\left(\mathrm{CH}_{2} \mathrm{CHCHCH}_{3}\right)$ and cyclopropylmethyl $\left(\mathrm{CH}_{2}-\mathrm{CHCH}_{2} \mathrm{CH}_{2}\right)$ isomers through the transition states with barriers (relative to $c-\mathrm{C}_{4} \mathrm{H}_{7}$ ) of 25.4 and $5.5 \mathrm{kcal} /$ mol, respectively. The $c-\mathrm{C}_{4} \mathrm{H}_{7}, 3$-buten-1-yl and 1-methallyl radicals could also undergo $\mathrm{H}$ elimination to form $\mathrm{H}+\mathrm{C}_{4} \mathrm{H}_{6}$. Among the isomeization and dissociation barriers, the ring- 

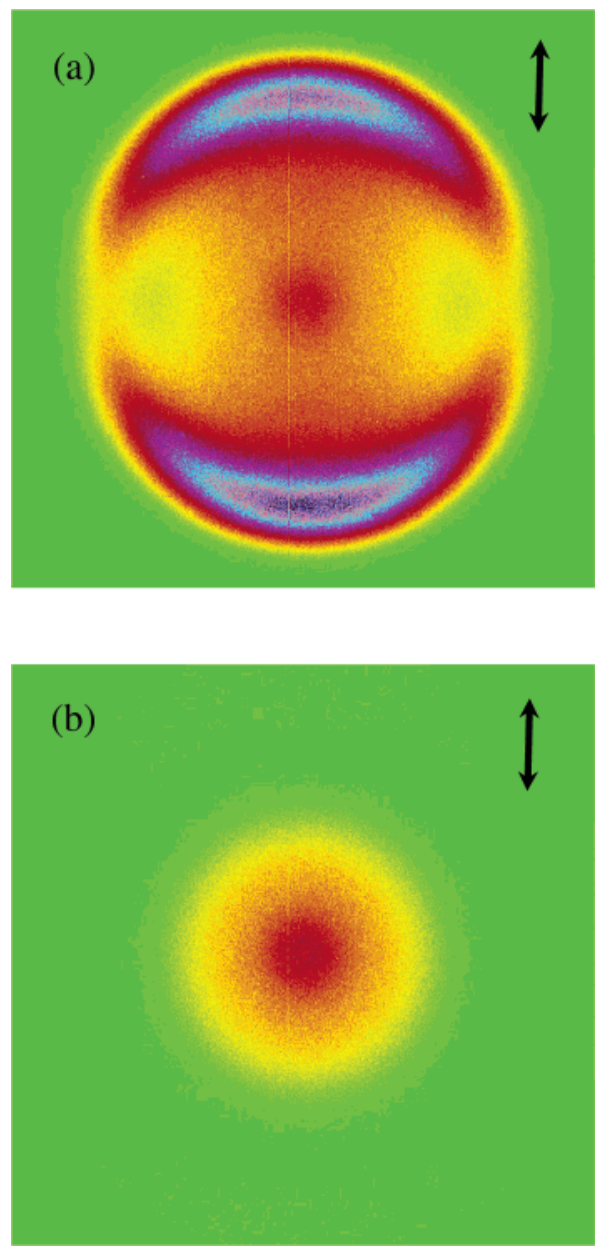

Figure 3. Raw images of the $c-\mathrm{C}_{4} \mathrm{H}_{7}$ fragments obtained at (a) $234+$ 157 and (b) $157 \mathrm{~nm}$, respectively. A high-translational energy component appearing in (a) but not in (b) reveals that there is a contribution of $c-\mathrm{C}_{4} \mathrm{H}_{7}$ fragments from 234 photodissociation with the radicals ionized by the $157 \mathrm{~nm}$ photons. Each image has a dimension of $861 \times$ 861 pixels.

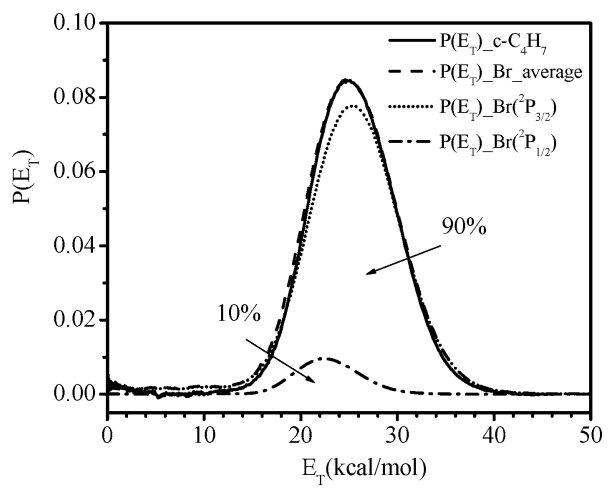

Figure 4. Total center-of-mass translational energy distributions derived from Figure 3, panels a and b, after subtraction (shown in solid line). Total center-of-mass translational energy distributions obtained from the weighted sum of the individual $\mathrm{Br}$ distributions in Figure 1, panels $a$ and $b$ (shown as the dashed line).

opening barrier $(28.3 \mathrm{kcal} / \mathrm{mol})$ for $c-\mathrm{C}_{4} \mathrm{H}_{7}$ to forming $\mathrm{CH}_{2}$ $\mathrm{CHCH}_{2} \mathrm{CH}_{2}$ is the primary step which governs the reactivity of $c-\mathrm{C}_{4} \mathrm{H}_{7}$ on the potential energy surface. Thus, one would expect that $c-\mathrm{C}_{4} \mathrm{H}_{7}$ radicals formed with internal energy more than $\sim 28$ $\mathrm{kcal} / \mathrm{mol}$ should be unstable to isomerization in the formation of 1-methylallyl radicals and possibly followed by hydrogen atom elimination. In contrast, our experiment detects $c-\mathrm{C}_{4} \mathrm{H}_{7}$ radicals with internal energies as high as $\sim 34.7 \mathrm{kcal} / \mathrm{mol}$. This stability at internal energies higher than the barrier can result if a significant fraction of the $\mathrm{C}-\mathrm{Br}$ fission events releasing between 14 and $20 \mathrm{kcal} / \mathrm{mol}$ to relative kinetic-energy partition enough of the remaining energy to rotation rather than vibration to leave the radical with a vibrational energy less than the 28 $\mathrm{kcal} / \mathrm{mol}$ barrier to isomerization. Assuming the recoil velocity vector is along the $\mathrm{C}-\mathrm{Br}$ bond direction at the equilibrium ground-state geometry of cyclobutyl bromide, an impulsive dissociation that imparts $16 \mathrm{kcal} / \mathrm{mol}$ of energy into relative kinetic energy, leaving the cyclobutyl radicals with a total internal energy of $32.7 \mathrm{kcal} / \mathrm{mol}$ (for the ones formed in conjunction with ground spin-orbit state $\mathrm{Br}$ atoms), must, by angular momentum conservation, impart about $16 \mathrm{kcal} / \mathrm{mol}$ of this to rotational energy, leaving the radical with too little vibrational energy to isomerize. The amount of rotational energy is so large that even if the partitioning to product rotation varies about this mean the cyclobutyl radicals will unlikely have enough vibrational energy to undergo isomerization. In other words, the $c-\mathrm{C}_{4} \mathrm{H}_{7}$ radicals, formed from the $\mathrm{C}-\mathrm{Br}$ bond fission events and detected by the $157-\mathrm{nm}$ photoionization, have an internal energy distribution ranging from 9.7 to $34.7 \mathrm{kcal} / \mathrm{mol}$ : the portion of the $c-\mathrm{C}_{4} \mathrm{H}_{7}$ radicals with a total internal energy higher than the dissociation barrier are stable to isomerization/ dissociation by virtue of the fraction of internal energy which is constrained by angular momentum conservation to be partitioned to rotational energy of the radical rather than vibrational energy. Conservation of angular momentum prevents these radicals from isomerizing and then dissociating.

B. Spin-Orbit Branching Ratio and REMPI Line Strength. This study focuses on the $\mathrm{C}-\mathrm{Br}$ bond fission to yield $c-\mathrm{C}_{4} \mathrm{H}_{7}$ and $\operatorname{Br}\left({ }^{2} \mathrm{P}_{1 / 2,3 / 2}\right)$ photofragments; other sources of producing atomic $\mathrm{Br}$ fragments such as the secondary photodissociation of $\mathrm{HBr}$ (produced from the primary photodissociation channel of $c-\mathrm{C}_{4} \mathrm{H}_{7} \mathrm{Br} \rightarrow \mathrm{C}_{4} \mathrm{H}_{6}+\mathrm{HBr}$ ) is assumed to be negligible. The spin-orbit branching ratio is determined by matching the total $\mathrm{C}-\mathrm{Br}$ bond fission $\mathrm{P}\left(\mathrm{E}_{\mathrm{T}}\right)$ from the kinetic-energy measurement of $\mathrm{Br}$ atoms, re-constructed by a weighted-sum the $\mathrm{P}\left(\mathrm{E}_{\mathrm{T}}\right)$ 's derived from the individual $\operatorname{Br}\left({ }^{2} \mathrm{P}_{3 / 2}\right)$ and $\operatorname{Br}\left({ }^{2} \mathrm{P}_{1 / 2}\right)$ fragments, to the $\mathrm{P}\left(\mathrm{E}_{\mathrm{T}}\right)$ determined from the $c-\mathrm{C}_{4} \mathrm{H}_{7}$ fragments. The normalized $\mathrm{P}\left(\mathrm{E}_{\mathrm{T}}\right)$ 's of both $\operatorname{Br}\left({ }^{2} \mathrm{P}_{3 / 2}\right)$ and $\operatorname{Br}\left({ }^{2} \mathrm{P}_{1 / 2}\right)$ atoms were first added together with an arbitrary weighting factor. The total $\mathrm{C}-\mathrm{Br}$ bond fission $\mathrm{P}\left(\mathrm{E}_{\mathrm{T}}\right)$ derived was then compared with the $\mathrm{P}\left(\mathrm{E}_{\mathrm{T}}\right)$ of $c-\mathrm{C}_{4} \mathrm{H}_{7}$ fragments. The weighting factor is then adjusted accordingly until a good agreement between the total $\mathrm{P}\left(\mathrm{E}_{\mathrm{T}}\right)$ from the $\mathrm{Br}$ fragments and the $\mathrm{P}\left(\mathrm{E}_{\mathrm{T}}\right)$ determined from the $c-\mathrm{C}_{4} \mathrm{H}_{7}$ is reached. The best fit $\mathrm{P}\left(\mathrm{E}_{\mathrm{T}}\right)$ 's for $\mathrm{C}-\mathrm{Br}$ bond fission event are displayed in Figure 4 with the dashed line for the $\mathrm{P}\left(\mathrm{E}_{\mathrm{T}}\right)$ determined from the $\mathrm{Br}$ atoms and the solid line for $\mathrm{P}\left(\mathrm{E}_{\mathrm{T}}\right)$ determined from the $c-\mathrm{C}_{4} \mathrm{H}_{7}$ signal. This corresponds to a branching ratio for $\operatorname{Br}\left({ }^{2} \mathrm{P}_{1 / 2}\right): \operatorname{Br}\left({ }^{2} \mathrm{P}_{3 / 2}\right)=0.11 \pm 0.07$. The uncertainty of 0.07 is determined by the standard deviation for several trials in fitting the $\mathrm{P}\left(\mathrm{E}_{\mathrm{T}}\right)$ 's. We have tested the line strength factor determined in this paper by using it to weigh the $\mathrm{Br}$ atom signals in the photodissociation of another system, bromomethylcyclopropane. The same line strength factor (within error bars) gives the required momentum match between the $\mathrm{Br}$ atom spectra and the radical velocity measurements. This also demonstrates that the line strength factors are reliable and not simply adjusting for an internal energy dependence to the radical's photoionization cross section. Indeed, we could not obtain such good fits in both systems if the radicals' photoionization cross sections varied with their internal energy.

We note that the isotopic effect from ${ }^{81} \mathrm{Br}\left({ }^{2} \mathrm{P}_{1 / 2,3 / 2}\right)$ may also influence the $\mathrm{P}\left(\mathrm{E}_{\mathrm{T}}\right)$ profile of $c-\mathrm{C}_{4} \mathrm{H}_{7}$ radicals as the ${ }^{81} \mathrm{Br}\left({ }^{2} \mathrm{P}_{1 / 2,3 / 2}\right)$ 


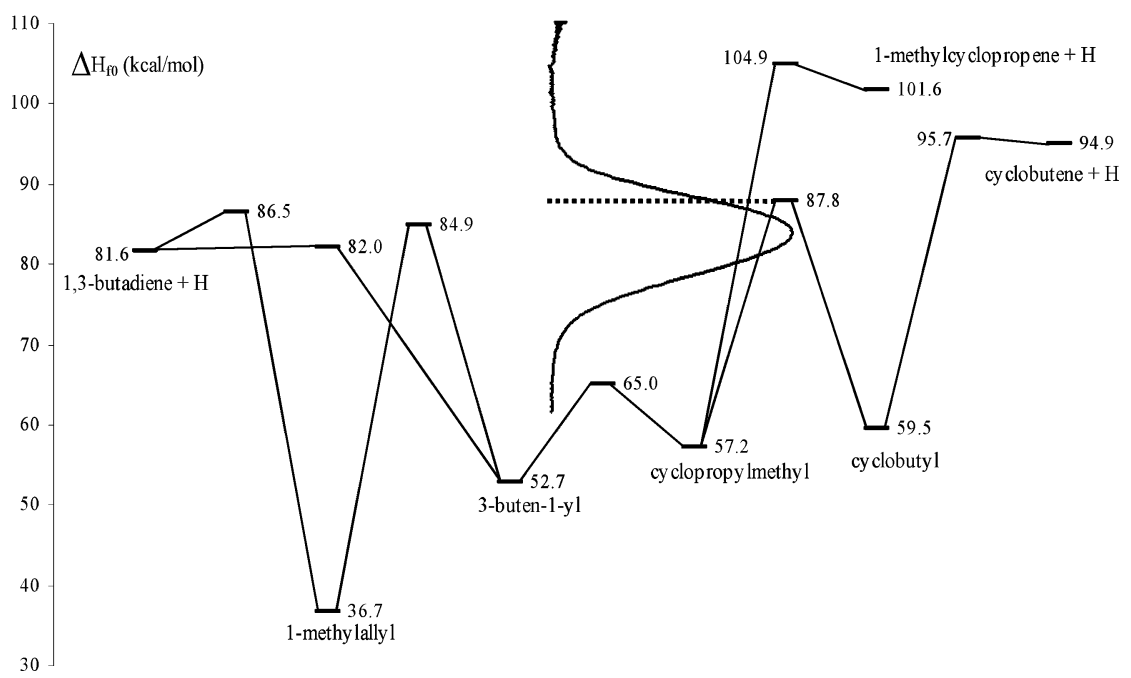

Figure 5. Energy diagram of the dissociation and isomerization channels of the $c-\mathrm{C}_{4} \mathrm{H}_{7}$ conformers. All values of $\Delta H_{f, 0 K}^{\circ}$ are from G3//B3LYP calculations. The overlaid curve is the internal energy distribution of the $c-\mathrm{C}_{4} \mathrm{H}_{7}$ radicals produced from photodissociation of cyclobutyl bromide at $234 \mathrm{~nm}$. Note we have determined this radical internal energy distribution from momentum conservation with the detected Br atoms and energy conservation, correcting for the fact that the radicals produced in coincidence with $\mathrm{Br}\left({ }^{2} \mathrm{P}_{1 / 2}\right)$ have $10.54 \mathrm{kcal} / \mathrm{mol}$ less internal energy.

isotopic fragments are recoiling from the $c-\mathrm{C}_{4} \mathrm{H}_{7}$ radical, it is expected that it would reduce the kinetic-energy release of the $c-\mathrm{C}_{4} \mathrm{H}_{7}$ radical and thus shift the $\mathrm{P}\left(\mathrm{E}_{\mathrm{T}}\right)$ to lower energy. However, it is found that the shift in the $\mathrm{P}\left(\mathrm{E}_{\mathrm{T}}\right)$ distribution due to the isotopic effect from ${ }^{81} \operatorname{Br}\left({ }^{2} \mathrm{P}_{1 / 2,3 / 2}\right)$ is negligibly small, less than $0.5 \mathrm{kcal} / \mathrm{mol}$.

In a typical ion imaging experiment involving halogen photofragments, the REMPI line strength factor is crucial in determining the spin-orbit branching ratio. However, there are large discrepancies among these factors measured by different research groups. The experiment here allows us to derive the relative line strength of the bromine REMPI at the wavelengths of 233.681 and $234.021 \mathrm{~nm}$. The spin-orbit branching ratio $\mathrm{N}\left[\mathrm{Br}\left({ }^{2} \mathrm{P}_{1 / 2}\right)\right] / \mathrm{N}\left[\mathrm{Br}\left({ }^{2} \mathrm{P}_{3 / 2}\right)\right]$ is proportional to the measured ion signal ratio $\mathrm{S}\left[\mathrm{Br}\left({ }^{2} \mathrm{P}_{1 / 2}\right)\right] / \mathrm{S}\left[\mathrm{Br}\left({ }^{2} \mathrm{P}_{3 / 2}\right)\right]$ according to the following equation:

$$
N\left[\operatorname{Br}\left({ }^{2} \mathrm{P}_{1 / 2}\right)\right] / N\left[\operatorname{Br}\left({ }^{2} \mathrm{P}_{3 / 2}\right)\right]=k S\left[\operatorname{Br}\left({ }^{2} \mathrm{P}_{1 / 2}\right)\right] / S\left[\operatorname{Br}\left({ }^{2} \mathrm{P}_{3 / 2}\right)\right]
$$

where $N(\mathrm{X})$ is the number of bromine atoms produced in the photodissociation event, $S(\mathrm{X})$ is the measured bromine ion signal intensity, and $k$ is the relative REMPI line strength at those two wavelengths.

Since the spin-orbit branching ratio of $\operatorname{Br}\left({ }^{2} \mathrm{P}_{3 / 2}\right)$ and $\operatorname{Br}\left({ }^{2} \mathrm{P}_{1 / 2}\right)$ from the photodissociation of cyclobutyl bromide at $234 \mathrm{~nm}$ has already been determined as mentioned above, the only parameter that is needed is the bromine ion signal intensity ratio. The total $m / e=79$ ion signal intensity is obtained by integrating the time-of-flight profile at the appropriate time window displayed on the oscilloscope where the signals are directly collected from the phosphor screen. The ratio $S\left[\mathrm{Br}\left({ }^{2} \mathrm{P}_{1 / 2}\right)\right] / S[\mathrm{Br}-$ $\left.\left({ }^{2} \mathrm{P}_{3 / 2}\right)\right]$ is measured to be 1.157 . When this value and a $N[\mathrm{Br}-$ $\left.\left({ }^{2} \mathrm{P}_{1 / 2}\right)\right] / N\left[\operatorname{Br}\left({ }^{2} \mathrm{P}_{1 / 2}\right)\right]$ value of 0.11 are plugged into the above equation, the constant $k$, i.e., the relative REMPI line strength of $\operatorname{Br}\left({ }^{2} \mathrm{P}_{3 / 2}\right)$ to $\operatorname{Br}\left({ }^{2} \mathrm{P}_{1 / 2}\right)$, is calculated to be $0.10 \pm 0.07$. This is notably smaller than 0.42 , the value measured by Jee et al. ${ }^{19}$ in their study on the $234 \mathrm{~nm}$ photodissociation of $\mathrm{Br}_{2}$. Although photodissociation of diatomic halogen molecules is the standard method of calibrating halogen atom REMPI line strengths, in Jee's study on $\mathrm{Br}_{2}$ at $234 \mathrm{~nm}$, there was a strong component of low kinetic energy $\mathrm{Br}^{+}$coming from nonresonant two-photon processes in both the $\operatorname{Br}\left({ }^{2} \mathrm{P}_{3 / 2}\right)$ and $\operatorname{Br}\left({ }^{2} \mathrm{P}_{1 / 2}\right)$ images obtained at
233.681 and $234.021 \mathrm{~nm}$, respectively. That low KE component is very sensitive to the two-photon wavelength and difficult to subtract from the total $\mathrm{Br}^{+}$signal to obtain the net on-resonance $\mathrm{Br}^{+}$signal. Therefore, the accuracy of linestrength ratio from their measurements may be limited.

C. Photofragment Angular Distributions. The use of a linearly polarized laser to photolyze cyclobutyl bromide and probe the $\operatorname{Br}\left({ }^{2} \mathrm{P}_{1 / 2,3 / 2}\right)$ atomic fragment with the same laser beam yields the product recoil angular distributions shown in Figure 6 , panels $b$ and $c$. The $\operatorname{Br}\left({ }^{2} \mathrm{P}_{1 / 2}\right)$ angular distribution in Figure $6 \mathrm{~b}$ is fit using the following expression:

$$
\mathrm{I}(\theta) \propto 1+\beta P_{2}(\cos \theta)
$$

where $\theta$ is the angle between the product recoil velocity and the polarization axis of the photolysis laser. $I(\theta)$ is the integrated signal over a certain speed range at angle $\theta$, and $P_{2}(\cos \theta)$ is the second-order Legendre polynomial. An anisotropy parameter of $1.67 \pm 0.03$ (the uncertainty is assigned based on the standard error from repeated measurements) is obtained for $\operatorname{Br}\left({ }^{2} \mathrm{P}_{1 / 2}\right)$ with the signal integrated over the speed range of $725 \sim 1250 \mathrm{~m} / \mathrm{s}$, indicating a very anisotropic distribution. (The anisotropy parameter $\beta$ can range from -1 to +2 , with -1 corresponding to perpendicular transition and +2 corresponding to parallel transition upon photoexcitation of the parent molecules.)

The angular distribution for the ground-state bromine (Figure $6 c)$, however, cannot be fit by eq 3 . The $\operatorname{Br}\left({ }^{2} \mathrm{P}_{3 / 2}\right)$ atoms, having spin-orbit angular momentum quantum number $(J)$ larger than $1 / 2$, may have an aligned $m_{\mathrm{J}}$ distribution that can influence the efficiency of the linearly polarized REMPI process. ${ }^{27-31}$ The detected $\operatorname{Br}\left({ }^{2} \mathrm{P}_{3 / 2}\right)$ angular distribution in Figure $6 \mathrm{c}$ is thus fit by

$$
\mathrm{I}(\theta) \propto 1+\beta_{2} P_{2}(\cos \theta)+\beta_{4} P_{4}(\cos \theta)
$$

Note that the coefficient $\beta_{2}$ in the above equation is influenced by the laboratory frame quadrupole alignment $A_{0}$ as well as the photofragment angular distribution, and therefore, it is not equal to the spatial anisotropy parameter $\beta$ in eq 4. By integrating the signal for $\operatorname{Br}\left({ }^{2} \mathrm{P}_{3 / 2}\right)$ over the speed range of $700 \sim 1370 \mathrm{~m} / \mathrm{s}$, we obtain anisotropy parameters $\beta_{2}=1.05 \pm 0.02$ and $\beta_{4}=$ $-0.08 \pm 0.003$. The anisotropy parameter and angular distribution analysis for the $\mathrm{Cl}\left({ }^{2} \mathrm{P}_{3 / 2}\right)$ fragment in the photodissociation 

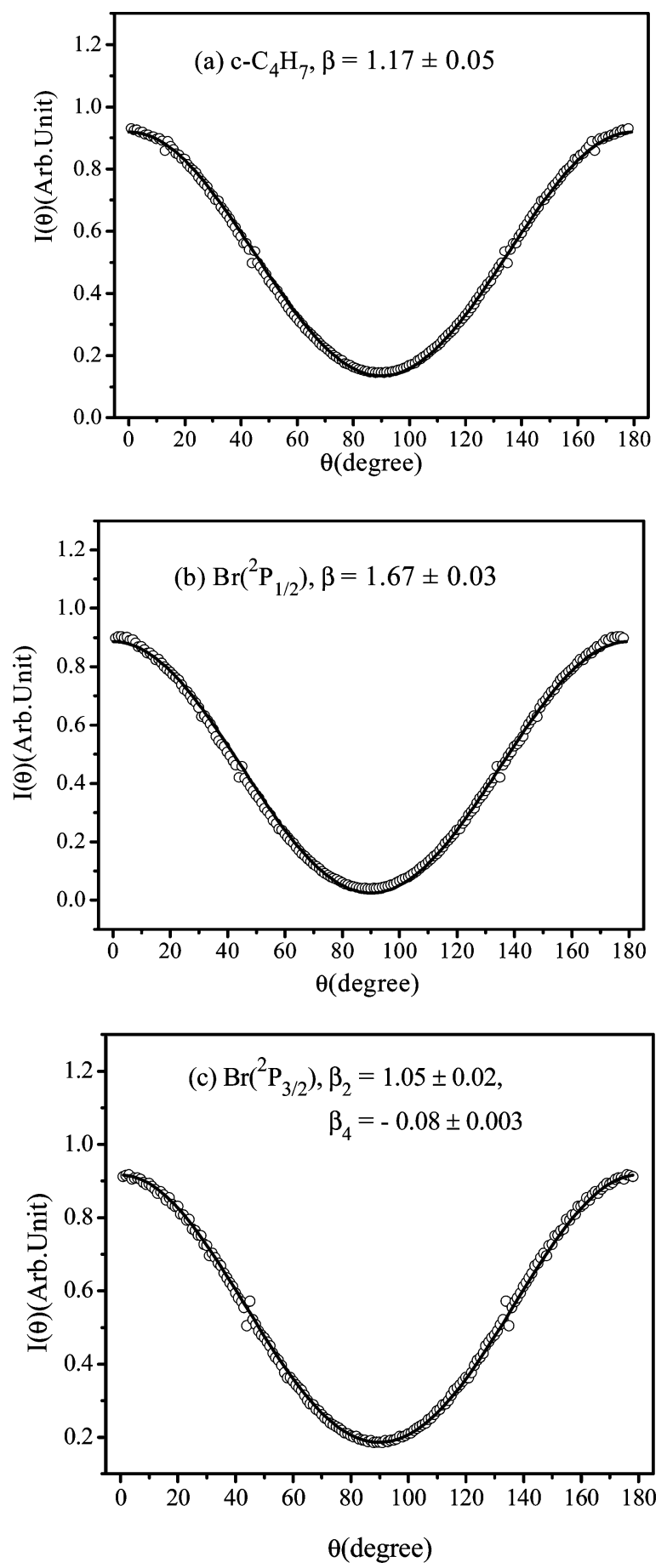

Figure 6. Fits for the angular distributions of (a) $c-\mathrm{C}_{4} \mathrm{H}_{7}$ fragment; (b) $\mathrm{Br}\left({ }^{2} \mathrm{P}_{1 / 2}\right)$ product; and (c) $\mathrm{Br}\left({ }^{2} \mathrm{P}_{3 / 2}\right)$.

study of allyl chloride have been done in a similar fashion. ${ }^{27}$ As suggested by Samartzis et al., ${ }^{30}$ it is possible to decouple the spatial anisotropy parameter $\beta$ from the vector alignment effect. Using the above $\beta_{2}$ and $\beta_{4}$ values and the equations [eqs 9 and 11] in their paper, the spatial recoil anisotropy parameter $\beta$ (without vector alignment effect) for $\operatorname{Br}\left({ }^{2} \mathrm{P}_{3 / 2}\right)$ is derived to be $1.12 \pm 0.02$.

Similar to our analysis for the $\operatorname{Br}\left({ }^{2} \mathrm{P}_{1 / 2}\right)$ fragments, an anisotropy parameter $\beta=1.17 \pm 0.05$ for the $c-\mathrm{C}_{4} \mathrm{H}_{7}$ radical is obtained by integrating the signal over the speed range of $1080 \sim 1870 \mathrm{~m} / \mathrm{s}$ and fitting with eq 3 (the fit is shown in Figure $6 a)$. On the basis of momentum conservation, the angular distribution of the $c-\mathrm{C}_{4} \mathrm{H}_{7}$ radical would precisely match with that of the $\operatorname{Br}\left({ }^{2} \mathrm{P}_{1 / 2,3 / 2}\right)$ cofragments. The anisotropy parameter

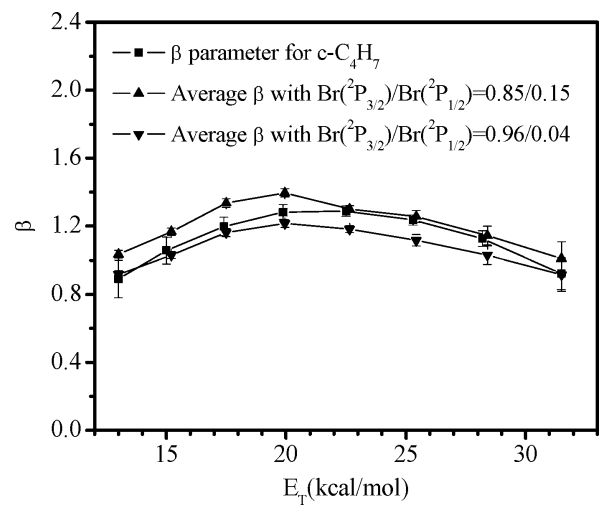

Figure 7. Comparison between the translational energy dependent anisotropy parameter of $c-\mathrm{C}_{4} \mathrm{H}_{7}$ fragment and the weight-averaged anisotropy parameter of $\mathrm{Br}\left({ }^{2} \mathrm{P}_{1 / 2}\right)$ and $\mathrm{Br}\left({ }^{2} \mathrm{P}_{3 / 2}\right)$.

of the total angular distribution for both $\operatorname{Br}\left({ }^{2} \mathrm{P}_{1 / 2}\right)$ and $\operatorname{Br}\left({ }^{2} \mathrm{P}_{3 / 2}\right)$ fragments could be obtained by the weighted sum of the anisotropy parameters $\beta=1.67 \pm 0.03$ for $\operatorname{Br}\left({ }^{2} \mathrm{P}_{1 / 2}\right)$ and $\beta=$ $1.12 \pm 0.02$ for $\operatorname{Br}\left({ }^{2} \mathrm{P}_{3 / 2}\right)$ with the spin-orbit branching ratio $\left(\operatorname{Br}\left({ }^{2} \mathrm{P}_{1 / 2}\right): \operatorname{Br}\left({ }^{2} \mathrm{P}_{3 / 2}\right)=0.11 \pm 0.07\right)$ determined in section $\mathrm{B}$. This anisotropy parameter for the total $\operatorname{Br}\left({ }^{2} \mathrm{P}_{1 / 2,3 / 2}\right)$ angular distribution is found to be $1.18 \pm 0.04$, which is in very good agreement with the $\beta$ value of $1.17 \pm 0.05$ for the momentum-matched $c-\mathrm{C}_{4} \mathrm{H}_{7}$ fragment after taking into account the uncertainty in each. This shows that the spin-orbit branching ratio determined by fitting the $\mathrm{P}\left(\mathrm{E}_{\mathrm{T}}\right)$ 's from the kinetic-energy measurements of $\operatorname{Br}\left({ }^{2} \mathrm{P}_{1 / 2,3 / 2}\right)$ atoms with that of the $c-\mathrm{C}_{4} \mathrm{H}_{7}$ cofragment is consistent with the anisotropy measurements. Further evidence is provided by comparing the speed dependent anisotropy for the cyclobutyl radical and the weighted average of that of the $\operatorname{Br}\left({ }^{2} \mathrm{P}_{1 / 2,3 / 2}\right)$ fragments. The result is presented in Figure 7 , where the anisotropy parameters as a function of center-of-mass kinetic energy release are shown. The weighting factors for the $\operatorname{Br}\left({ }^{2} \mathrm{P}_{3 / 2}\right)$ anisotropy parameter and that of the $\operatorname{Br}\left({ }^{2} \mathrm{P}_{1 / 2}\right)$ fragment in each specific kinetic energy range are derived from their relative contribution to the total $\mathrm{P}\left(\mathrm{E}_{\mathrm{T}}\right)$ at that kinetic energy as shown in Figure 4. Considering the 0.07 uncertainty of the $\operatorname{Br}\left({ }^{2} \mathrm{P}_{1 / 2,3 / 2}\right)$ spin-orbit branching ratio, two averaged speed dependent $\beta$ curves for the bromine fragments are shown in Figure 7 with each corresponding to a limiting spin-orbit branching fraction. It is obvious that the speed dependent $\beta$ curve for the $c-\mathrm{C}_{4} \mathrm{H}_{7}$ radical falls between the two limiting $\operatorname{Br}\left({ }^{2} \mathrm{P}_{1 / 2,3 / 2}\right)$ averaged curves, Thus our experimentally determined $\operatorname{Br}\left({ }^{2} \mathrm{P}_{\mathrm{J}}\right)$ spin-orbit branching ratio and the relative REMPI linestrength factor are further confirmed.

Figure 8 shows the ultraviolet absorption spectrum of cyclobutyl bromide; the absorption band is similar to that of methyl bromide but shifted to the red. Thus, we expect the 234$\mathrm{nm}$ photon excites a nonbonding electron of $\mathrm{Br}$ to the $\sigma^{*}(\mathrm{C}-$ $\mathrm{Br}$ ) orbital, promoting the molecule to potential energy surfaces of $c-\mathrm{C}_{4} \mathrm{H}_{7} \mathrm{Br}$ which are repulsive along the $\mathrm{C}-\mathrm{Br}$ bond. It is interesting to compare the spatial anisotropy parameters for $\operatorname{Br}\left({ }^{2} \mathrm{P}_{3 / 2}\right)$ and $\operatorname{Br}\left({ }^{2} \mathrm{P}_{1 / 2}\right)$ with the limiting value of 2 (from a parallel transition moment) and with each other. The $\beta$ value of 1.67 for $\operatorname{Br}\left({ }^{2} \mathrm{P}_{1 / 2}\right)$ indicates that the initially excited repulsive $\mathrm{n} \sigma^{*}(\mathrm{C}-\mathrm{Br})$ state of cyclobutyl bromide at $234 \mathrm{~nm}$ is accessed largely through a parallel transition and asymptotically dissociates into $\mathrm{Br}\left({ }^{2} \mathrm{P}_{1 / 2}\right)+c-\mathrm{C}_{4} \mathrm{H}_{7}$ fragments. This repulsive state is analogous to the ${ }^{3} \mathrm{Q}_{0}$ state of the $\mathrm{CH}_{3} \mathrm{Br}$ molecule. ${ }^{8}$ The deviation of $\operatorname{Br}\left({ }^{2} \mathrm{P}_{1 / 2}\right)$ angular distribution from the $\cos ^{2} \theta$ behavior may result from several reasons. First, photoexcitation of cyclobutyl bromide at $234 \mathrm{~nm}$ may involve a small overlapping absorption to the excited states analogous to the ${ }^{3} \mathrm{Q}_{1}$ state or the ${ }^{1} \mathrm{Q}_{1}$ states 


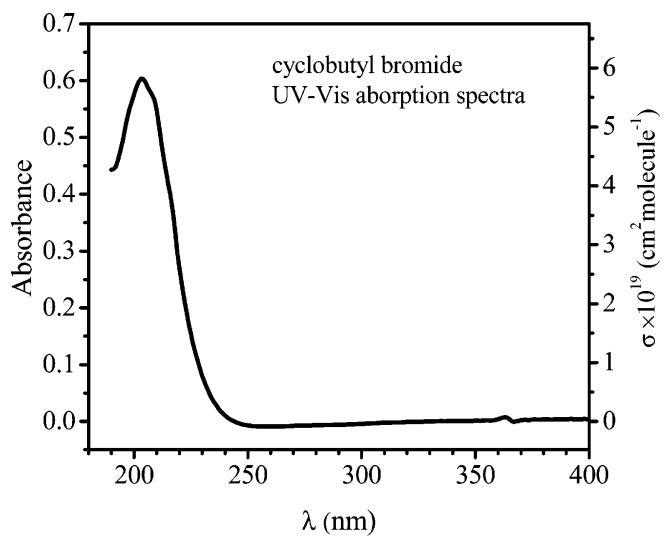

Figure 8. Gas-phase ultraviolet absorption spectrum of cyclobutyl bromide.

of the $\mathrm{CH}_{3} \mathrm{Br}$ molecule accessed by perpendicular transition. Nonadiabatic curve crossing from the ${ }^{1} \mathrm{Q}_{1}$ diabat to the ${ }^{3} \mathrm{Q}_{0}$ diabat analogue in cyclobutyl bromide may proceed along the $\mathrm{C}-\mathrm{Br}$ bond stretching coordinate and produce $\mathrm{Br}\left({ }^{2} \mathrm{P}_{1 / 2}\right)$ fragments adiabatically, thus contributing some perpendicular character to the $\operatorname{Br}\left({ }^{2} \mathrm{P}_{1 / 2}\right)$ fragment angular distribution. In addition, the vibrational bending motion in the excited parent molecule will also decrease the dissociation product recoil anisotropy. Likewise, the $\operatorname{Br}\left({ }^{2} \mathrm{P}_{3 / 2}\right)$ atoms may also be produced from dissociation on the ${ }^{3} \mathrm{Q}_{1}$ state or the ${ }^{1} \mathrm{Q}_{1}$ states diabatically and via the curve crossing, avoided at nonsymmetric geometries, between the ${ }^{3} \mathrm{Q}_{0}$ and the ${ }^{1} \mathrm{Q}_{1}$ states. Indeed, the measured anisotropy parameter of 1.12 for $\operatorname{Br}\left({ }^{2} \mathrm{P}_{3 / 2}\right)$, having a significant parallel character, but more perpendicular character than that of the $\operatorname{Br}\left({ }^{2} \mathrm{P}_{1 / 2}\right)$ fragment, indicates that absorption to the ${ }^{3} \mathrm{Q}_{1}$ state may play a role. Further investigation regarding the cyclobutyl bromide potential energy surfaces is needed to facilitate understanding the details of this process.

\section{Conclusion}

The photodissociation of cyclobutyl bromide has been studied at $234 \mathrm{~nm}$ using two-dimensional product velocity map imaging technique. By momentum match of the $\mathrm{P}\left(\mathrm{E}_{\mathrm{T}}\right)$ derived from the $c-\mathrm{C}_{4} \mathrm{H}_{7}$ photofragment with that from the bromine products, the $\operatorname{Br}\left({ }^{2} \mathrm{P}_{1 / 2}\right) / \mathrm{Br}\left({ }^{2} \mathrm{P}_{3 / 2}\right)$ branching ratio is determined to be $0.11 \pm$ 0.07, and the $\operatorname{Br}\left({ }^{2} \mathrm{P}_{1 / 2}\right) / \mathrm{Br}\left({ }^{2} \mathrm{P}_{3 / 2}\right)$ REMPI linestrength ratio is calibrated to be $0.10 \pm 0.07$ for the resonance wavelengths of 233.681 and $234.021 \mathrm{~nm}$. The observed stability of the $c-\mathrm{C}_{4} \mathrm{H}_{7}$ photofragments, detected with $157 \mathrm{~nm}$ VUV photoionization, indicates the radicals with high total internal energy do not isomerize because much of that internal energy is partitioned in part to rotational rather than vibrational energy. These experiments establish a photolyic source for cyclobutyl radicals and determine their internal energy distribution.
Acknowledgment. This work was supported by the National Science Foundation under Grant No. CHE-0403471. The authors acknowledge Praket Prakash Jha for his assistance in taking the ultraviolet absorption spectrum.

\section{References and Notes}

(1) Mueller, J. A.; Miller, J. L.; Butler, L. J.; Qi, F.; Sorkhabi, O.; Suits, A. G. J. Phys. Chem. A 2000, 104, 11261.

(2) Morton, M. L.; Butler, L. J.; Stephenson, T. A.; Qi, F. J. Chem. Phys. 2002, 116, 2763.

(3) Morton, M. L.; Miller, J. L.; Butler, L. J.; Qi, F. J. Phys. Chem. A 2002, 106, 10831 .

(4) Miller, J. L.; Krisch, M. J.; Butler, L. J.; Shu, J. N. J. Phys. Chem. A 2005, 109, 4038.

(5) McCunn, L. R.; Krisch, M. J.; Liu, Y.; Butler, L. J.; Shu, J. N. J. Phys. Chem. A 2005, 109, 6430.

(6) King, D. K.; Gilbert, R. G. Int. J. Chem. Kinet. 1980, 12, 339

(7) Blank, D. A.; Sun, W. Z.; Suits, A. G.; Lee, Y. T.; North, S. W.; Hall, G. E. J. Chem. Phys. 1998, 108, 5414.

(8) Gougousi, T.; Samartzis, P. C.; Kitsopoulos, T. N. J. Chem. Phys. 1998, 108, 5742 .

(9) Zhu, R. S.; Tang, B. F.; Ji, L.; Tang, Y.; Zhang, S.; Zhang, B. Opt. Commun. 2004, 235, 325 .

(10) Park, M. S.; Lee, K. W.; Jung, K. H. J. Chem. Phys. 2001, 114, 10368

(11) Kawasaki, M.; Kasatani, K.; Sato, H.; Shinohara, H.; Nishi, N. Chem. Phys. 1984, 88, 135.

(12) Lee, Y. R.; Lin, S. M. J. Chem. Phys. 1998, 108, 134.

(13) Vanveen, G. N. A.; Baller, T.; Devries, A. E.; Shapiro, M. Chem. Phys. 1985, 93, 277.

(14) Matheu, D. M.; Green, W. H.; Grenda, J. M. Int. J. Chem. Kinet 2003, 35, 95 .

(15) Moss, R. A.; Sauers, R. R.; Zheng, F. M.; Fu, X. L.; Bally, T.; Maltsev, A. J. Am. Chem. Soc. 2004, 126, 8466.

(16) Arnold, P. A.; Cosofret, B. R.; Dylewski, S. M.; Houston, P. L.; Carpenter, B. K. J. Phys. Chem. A 2001, 105, 1693.

(17) Clegg, S. M.; Parsons, B. F.; Klippenstein, S. J.; Osborn, D. L. J. Chem. Phys. 2003, 119, 7222.

(18) Freitas, J. E.; Hwang, H. J.; Ticknor, A. B.; Elsayed, M. A. Chem. Phys. Lett. 1991, 183, 165.

(19) Jee, Y. J.; Jung, Y. J.; Jung, K. H. J. Chem. Phys. 2001, 115, 9739.

(20) Heck, A. J. R.; Chandler, D. W. Annu. Rev. Phys. Chem. 1995, 46,335

(21) Eppink, A. T. J. B.; Parker, D. H. Rev. Sci. Instrum. 1997, 68 3477.

(22) Sato, Y.; Matsumi, Y.; Kawasaki, M.; Tsukiyama, K.; Bersohn, R. J. Phys. Chem. 1995, 99, 16307.

(23) Schultz, J. C.; Houle, F. A.; Beauchamp, J. L. J. Am. Chem. Soc 1984, 106, 7336

(24) Curtiss, L. A.; Redfern, P. C.; Rassolov, V.; Kedziora, G.; Pople, J. A. J. Chem. Phys. 2001, 114, 9287.

(25) Dribinski, V.; Ossadtchi, A.; Mandelshtam, V. A.; Reisler, H. Rev. Sci. Instrum. 2002, 73, 2634.

(26) Miller, J. L. J. Chem. Phys. A 2004, 108, 2268.

(27) Liu, Y.; Butler, L. J. J. Chem. Phys. 2004, 121, 11016

(28) Rakitzis, T. P.; Kandel, S. A.; Alexander, A. J.; Kim, Z. H.; Zare, R. N. J. Chem. Phys. 1999, 110, 3351.

(29) Rakitzis, T. P.; Zare, R. N. J. Chem. Phys. 1999, 110, 3341.

(30) Samartzis, P. C.; Bakker, B. L. G.; Rakitzis, T. P.; Parker, D. H.; Kitsopoulos, T. N. J. Chem. Phys. 1999, 110, 5201.

(31) Bass, M. J.; Brouard, M.; Clark, A. P.; Vallance, C.; MartinezHaya, B. Phys. Chem. Chem. Phys. 2003, 5, 856. 